\title{
O que pensam os estudantes sobre a formação profissional em Educação Física
}

http://dx.doi.org/10.11606/1807-5509201800020263

\author{
Rubiane Giovani FONSECA* \\ Larissa Michelle LARA**
}

*Departamento de Educação Física,

Universidade Estadual de Londrina, Londrina, PR, Brasil.

${ }^{* *}$ Departamento de Educação Física, Universidade Estadual de Maringá, Maringá,

PR, Brasil.

\section{Resumo}

Este estudo teve como propósito verificar o que pensam os estudantes sobre o processo de formação profissional e quais as orientações dos próprios alunos para a seleção de conhecimentos considerados relevantes para subsidiar sua atuação profissional. Para tanto, optamos pela técnica de Grupos Focais, com dois grupos de estudantes de Educação Física da Universidade Estadual de Maringá: um com sete alunos de primeiro ao terceiro ano do curso e o outro constituído por cinco alunos do terceiro e quarto ano do curso. Cada encontro originou dados de vídeo e áudio, transcrito e analisado posteriormente de forma a identificar padrões relacionados e aplicados ao problema de estudo. Identificamos duas categorias temáticas: a) Considerações sobre o curso de formação e expectativas para o campo profissional na Educação Física, que retratou o impacto da configuração curricular do curso e o impacto da ação docente na orientação profissional; b) Uso dos conhecimentos pelos estudantes de Educação Física, que descreve as características das redes de conhecimentos estabelecidas pelos estudantes no processo de formação. Tais categorias demonstraram que as demandas no mercado de trabalho levou a área a adaptar seus conteúdos e currículos, embora tais mudanças não tenham refletido nas condições da formação profissional, nem tampouco contemplaram as concepções dos docentes em relação ao ensino profissional, ressaltando fragilidades na lógica da formação universitária.

Palavras-Chave: Escolhas profissionais; Grupo focal; Conhecimento; Ensino profissional.

\section{Introdução}

A formação profissional na Educação Física tem valorizado cada vez mais a orientação científica da prática profissional, procurando se afastar da prática pautada na tentativa e erro e se aproximando cada vez mais de alguma base teórica que justifique as açóes profissionais. Tal 'aura' científica da prática profissional reflete na configuração da formação e na natureza da produção do conhecimento na Educação Física.

Segundo GamboA ${ }^{1}$, ao olhar para a produção do conhecimento recente na Educação Física, principalmente após a década de 1990, observase um crescente interesse pelas matrizes teóricas e pelo diagnóstico de seus conteúdos, tanto nas ciências naturais quanto humanas e sociais, indicando deslocamento de interesses das questóes instrumentais, técnicas e metodológicas para as teóricas e epistemológicas da área.

No entanto, apesar da valorização da dimensão científica da área como forma de garantir respaldo acadêmico nos últimos anos, a produçấo de conhecimento ainda não responde as questóes profissionais sobre o que vem a ser uma intervenção de qualidade, o que é ser um profissional habilidoso ou sobre quais as necessidades que balizam a formaçáo profissional para a preparaçáo de experts. No estudo de FrIzzo $^{2}$ sobre a produção de conhecimento em um programa de pós-graduação, ele identificou que a 
natureza teórico-metodológica dos estudos de mestrado e doutorado no período de 2000 até 2009 recaíam para o enfoque empírico-analítico (73\%) contra apenas $23 \%$ com enfoque fenomenológico-hermenêutico e $4 \%$ com o enfoque crítico-dialético. Os testes físicos e psicomotores representam mais da metade (54\%) das técnicas utilizadas nos estudos e a objetividade é adotada em mais de $72 \%$ das pesquisas.

Para Frizzo ${ }^{2}$, apesar da produção de conhecimento ter avançado em constatar problemas, a produção está distante do contexto histórico social que envolve as questóes profissionais. Uma explicação para o perfil descontextualizado do conhecimento produzido é o colonialismo epistemológico das ciências mãe. Segundo Gamboa $^{1}$, as teorias científicas oriundas da Psicologia, Fisiologia, Sociologia e Biomecânica contribuíram com hipóteses, teses e abstraçóes nas explicaçóes sobre os fenômenos da motricidade, partindo da teoria para o fenômeno e voltando para a teoria. 'O ponto de partida e o ponto de chegada são as teorias sociológicas, psicológicas, fisiológicas e não a Educação Física, que funciona como campo de passagem'1 (p. 26).

Idealizando o papel do conhecimento cientifico para a formaçáo profissional, ele seria responsável por fornecer as bases conceituais e epistemológicas que orientam o entendimento dos mecanismos que compóem a intervenção profissional. Já as estratégias de ação e os saberes que balizam as decisões profissionais comporiam o saber fazer da profissão. O saber fazer são as açóes e tarefas relativas à como, quando e porque intervir, conforme a natureza do papel social da intervenção profissional. Nesse caso, o saber fazer tem características próprias e, portanto, um status epistêmico próprio ${ }^{3}$, que orienta a forma de agir e tomar decisóes que não é diretamente compatível com o saber acadêmico produzido nas universidades.

A técnica, como um elemento que compóe a prática profissional, é saber vivo inserido nas práticas sociais dos sujeitos, sendo dificilmente capturada de modo integral em discursos que "sistematizam" por meio da ciência ${ }^{3}$. Talvez, por isso, a técnica esteja inserida nas disciplinas dos cursos de formação profissional como se fosse autoexplicativa. A chamada relação "teoria e prática" sugere que haja fundamentaçáo teórica para o entendimento dos domínios técnicos de uma ação mas, na verdade, essa ideia representa a crença hierárquica na correspondência entre conhecimento acadêmicocientífico e técnico profissional, haja vista que são saberes de caráter diferentes.
Entendendo a Educação Física como prática social, os conhecimentos que orientam a profissão devem ser baseados em questóes que a prática de fato coloca, fornecendo bases consistentes que possibilitem ao profissional interagir, adaptar, transformar e agir, sabendo analisar e estimular as potencialidades do movimentar-se no meio em que vive, superando o distanciamento entre universidade e campo profissional. Contudo, isso não quer dizer que o profissional deve estar aquém das formulaçôes científicas e dos conhecimentos fundamentais para sua profissão, mas deve se apoiar nas questões que estão presentes no seu cotidiano de intervenção para possibilitar uma leitura da realidade em que está inserido.

Em relativamente pouco tempo, o mercado exigiu profissionais com vasta capacidade operacional e habilidades comportamentais, assim como as universidades passaram a se ajustar a essas mudanças. Quanto mais o mercado de trabalho se torna competitivo e exigente, mais complexa se torna a organizaçáo e estruturação dos conhecimentos necessários para sustentar a formação de profissionais na universidade. Como consequência, as mudanças nas características do mercado impactaram no perfil do estudante universitário.

$\mathrm{Na}$ trajetória do ensino universitário, o aluno modelo para a carreira acadêmica era aquele que dispunha de tempo para estudar; tinha idade, formação intelectual que transcendia aos conteúdos escolares, financiamento familiar, disposição para atividades diversificadas social e culturalmente que, enfim, pertenciam à camada privilegiada da sociedade que investia na manutenção e melhoria de suas condiçóes. O aluno universitário de hoje é aquele que procura a forma mais rápida e dinâmica possível para se inserir no mercado de trabalho. Não dispõe de condições apropriadas para estudar, trabalha durante o dia e estuda no período da noite, com pouca disponibilidade de tempo para as atividades que transcendem o ensino e que, por isso, raramente estáo engajados nas atividades de pesquisa, cultura ou encontros científicos ${ }^{4}$.

Daí decorrem as questóes: Como ter um feedback sobre o processo de formação? Como reconhecer a capacidade de articular princípios e teorias no momento de tomar uma decisão? Para MarCon ${ }^{5}$, pensar na prática profissional nos cursos de formação acaba sendo uma manifestaçáo cobrada apenas em momentos como o estágio curricular e nas experiências extracurriculares vividas como aluno ou já como profissionais egressos. As mudanças observadas em 
relação às características dos universitários representam um quadro que vem se instalando nas universidades brasileiras e remete a mudanças de valores no papel formativo das instituiçốes.

Como acessar essas informaçóes e como criar alternativas para compreender a relaçáo dos conteúdos que fazem parte da formação de um profissional? Consideramos que as pesquisas com universitários podem ser um grande "termômetro" para a constatação das condiçóes da preparação profissional. Seja analisando uma prática pedagógica ou ministrando-a, as decisôes metodológicas serão tomadas pelos estudantes "a partir dos conhecimentos que sejam relevantes, significativos e salientes na base de conhecimentos, os quais, frequentemente, não terâo sido construídos somente no programa de formação inicial, mas também nas experiências de vida do estudante-professor" ${ }^{5}$ (p. 65).

O processo de formação universitária traz consigo modificações nos vínculos estabelecidos pelos estudantes, nos papéis sociais e na rotina de vida, provocando alteraçóes que exigem flexibilidade e autonomia do estudante, potencializadas com a exploração das dimensóes profissionais ao longo do ensino universitário ${ }^{6}$. Desse modo, o estudo com universitários, além de contribuir com a elaboraçáo dos currículos de formação, também contribui na avaliação da trajetória profissional.

Nesse sentido, este estudo pautou-se pela seguinte questão: como os estudantes orientam suas escolhas e atribuem relevância aos conteúdos que aprendem na universidade? Partimos do pressuposto de que a formação universitária está assentada na ideia de que o conhecimento acadêmico-científico pode servir de base para orientar a prática profissional. Tal preocupação nos levou ao propósito de verificar o que pensam os estudantes sobre o processo de formação profissional e quais as orientaçóes dos próprios alunos para a seleção de conhecimentos considerados relevantes para subsidiar sua atuação profissional.

\section{Método}

A formação profissional é um cenário repleto de elementos que extrapolam o contexto formalizado dos conteúdos disciplinares e, constantemente, é reordenado e contextualizado para cada decisão profissional. Para viabilizar uma leitura desta realidade na ótica dos estudantes, optamos por utilizar as diretrizes da abordagem qualitativa de pesquisa ${ }^{7}$.

$O$ estudo se qualifica por ser de natureza exploratória e descritiva ${ }^{8}$, já que pretende levantar informaçóes preliminares e descrever as estratégias e concepções dos estudantes de Educação Física sobre sua formação profissional. Para a escolha do método de pesquisa partimos do pressuposto de que a sociedade é entendida por estruturas, com regras e conhecimentos compartilhados e tácitos que tornam a interação social possível e aceita ${ }^{9}$. Na perspectiva da interatividade, temos a necessidade de explorar os posicionamentos e juízos pessoais e coletivos para possibilitar o entendimento dos fenômenos em análise. A técnica de grupos focais atendeu a essa perspectiva e foi escolhida por se ajustar adequadamente às intençóes dessa pesquisa.

Como nosso objeto de estudo refere-se às perspectivas dos próprios alunos sobre o profissional de Educação Física optamos por investigar alunos do curso de bacharelado e licenciatura levando em consideração a diversidade de campos de atuação na área. A pesquisa desenvolveu-se nas dependências do Curso de Educação Física da Universidade Estadual de Maringá, contando com alunos de primeiro, segundo, terceiro e quarto anos. Dessa forma, convenientemente, foram realizados convites para uma reuniáo explicativa sobre a pesquisa, para uma turma de cada ano do curso de bacharelado e licenciatura em Educaçáo Física. Nessa reunião, os objetivos e a dinâmica dos grupos focais foram apresentados, assim como o cronograma das reuniôes. Esclarecemos que, para a participação na pesquisa, era indicado apenas os alunos que não estivessem retidos nas séries, de modo a evitar variáveis que poderiam comprometer as representações sobre a formação.

Inicialmente, pensamos em delimitar os grupos para até quatro alunos de todos os anos do curso $\left(1^{\circ}, 2^{\circ}, 3^{\circ}\right.$ e $\left.4^{\circ}\right)$ que seriam distribuídos em dois grupos (grupo $\mathrm{A}-1^{\circ}$ e $2^{\circ}$ anos; Grupo $\mathrm{B}-3^{\circ}$ e $4^{\circ}$ anos). Essa distribuição possibilitaria que as discussóes fossem estimuladas pela proximidade de grau de formação no curso e não ficassem restritas ao mesmo patamar de repertório de conhecimentos, como aconteceria se fosse um grupo focal para cada ano de formação, além de facilitar o processo de pesquisa por parte dos pesquisadores na posterior organização dos dados. 
Entretanto, dos 18 graduandos interessados no primeiro contato, sete se fizeram presentes no primeiro encontro e, em sua maioria, do primeiro e segundo anos do curso. Apenas um aluno estava no terceiro ano. Seguindo a estrutura curricular à época, o primeiro ano do curso tinha o núcleo comum de disciplinas e, a partir do segundo ano os alunos definiam a habilitação profissional para licenciatura ou bacharelado. Devido à desproporcionalidade de participantes no primeiro grupo, em sua grande maioria na licenciatura ou prestes a escolher esta habilitação, iniciamos nova rodada de convites para alunos do terceiro e quarto anos do bacharelado em Educação Física com a intenção de organizar um segundo grupo focado nas etapas finais da formação inicial. A partir dos convites, tivemos a presença de seis bacharéis do terceiro ano e seis do quarto ano, dos quais, apenas cinco deram sequência aos encontros.

O QUADRO 1 ilustra os alunos participantes no estudo, a idade, série e o rol da frequência de intervençôes ao longo das entrevistas:

QUADRO 1 - Frequência das intervenções de cada participante dos grupos A e B.

\begin{tabular}{|c|c|c|c|}
\hline \multicolumn{4}{|c|}{ GRUPO A (3 ENCONTROS) } \\
\hline Participante & Idade & Série & Intervençóes \\
\hline Participante 3 & 19 & 1 & 92 \\
\hline Participante 7 & 21 & 2 & 59 \\
\hline Participante 4 & 17 & 1 & 52 \\
\hline Participante 6 & 22 & 2 & 51 \\
\hline Participante 2 & 18 & 1 & 50 \\
\hline Participante 5 & 22 & 3 & 23 \\
\hline Participante 1 & 20 & 2 & 21 \\
\hline \multicolumn{3}{|l|}{ Total de Intervençóes } & 348 \\
\hline \multicolumn{4}{|c|}{ GRUPO B (1 ENCONTRO) } \\
\hline Participante 1 & 23 & 3 & 48 \\
\hline Participante 3 & 21 & 4 & 43 \\
\hline Participante 2 & 21 & 3 & 41 \\
\hline Participante 4 & 21 & 4 & 28 \\
\hline Participante 5 & 21 & 4 & 22 \\
\hline \multicolumn{3}{|l|}{ Total de Intervençóes } & 182 \\
\hline
\end{tabular}

Com base em orientaçóes de alguns pesquisadores ${ }^{10-14}$ realizamos quatro encontros: três encontros com o Grupo A e um encontro com o Grupo B. O segundo grupo teve o objetivo de realçar as diferenças entre os níveis de formação e a investigação de informaçôes obtidas com o primeiro grupo.

Conforme a disponibilidade da maioria dos alunos, os encontros foram realizados no segundo período letivo anual, fator que prejudicou a participação dos estudantes nos últimos anos de formação. As atividades curriculares, como os estágios e o trabalho de conclusão de curso, afetaram diretamente na disponibilidade dos universitários para os grupos focais. Dessa maneira, o Grupo B concretizou um encontro. Considerando as orientaçóes de Krueger, o número de grupo e de sessóes, depende, necessariamente, da homogeneidade e suficiência das informaçôes obtidas para se atingir os objetivos. Sendo assim, apesar da limitação da disponibilidade dos participantes para novos encontros, o Grupo $\mathrm{B}$ apresentou mais de $50 \%$ de intervençóes em um encontro (ver QUADRO 1), se comparado às intervençóes dos três encontros do grupo $\mathrm{A}$ e, portanto, foi suficiente para contribuir com as análises sobre a formação profissional na Educação Física.

Para o primeiro encontro no Grupo A, elaboramos um roteiro de discussóes baseado nos tipos de questóes propostas por KRUEGER ${ }^{13}$ relacionadas às: justificativas da escolha pelo curso de Educação Física; preferências quanto às disciplinas e didáticas de professores; visão de cada habilitação (licenciatura e bacharelado); correspondência das disciplinas com o campo de atuação da Educação Física; habilidades consideradas 
importantes para o profissional de Educação Física; e se os acadêmicos estão sendo formados para adquirir essas habilidades. As informações ofereceram os primeiros elementos sobre a caracterizaçáo do curso na ótica dos próprios alunos, as referências que os levaram a escolher a Educação Física e a visão de cada habilitação. No segundo encontro com o Grupo A, levantamos questóes sobre: $\mathrm{O}$ que é ser um profissional de Educação Física?; Qual a relação da área com outras áreas no mercado de trabalho?; Quais as principais características que distinguem um profissional de Educação Física de outros profissionais? Também foram entregues algumas situaçóes-problema do campo de intervenção da Educação Física para que os alunos pudessem elencar os conhecimentos que consideravam mais importantes para solucionar cada situação. $\mathrm{O}$ terceiro encontro com o Grupo A foi iniciado com questóes sobre a visão do processo de aprendizagem que eles estavam vivenciando e como viam a correspondência desse processo com as demandas do campo de trabalho, já que, nas reuniōes anteriores, a preocupação em acompanhar a dinamicidade da área foi latente. $\mathrm{Na}$ sequência, abordamos as dificuldades de se aprender novos conteúdos e quais os caminhos para resolver esse problema.

A reuniáo com o Grupo B ocorreu no final do ano letivo de 2009 e, portanto foi o único encontro realizado. Após o preenchimento do questionário de caracterização do participante e das questóes ligadas à escolha do curso, preferências sobre as disciplinas e as habilidades consideradas relevantes aos profissionais, foi realizada uma dinâmica que partiu da seguinte questão: Que tipo de profissional de Educação Física sou eu? Os participantes deveriam apontar três respostas na forma de tópicos no papel e depois falar sobre cada um deles. Essa dinâmica permitiu que eles externalizassem as representaçóes que tinham sobre como é ser um profissional de Educação Física e possibilitou explorar de forma mais abrangente as questóes relacionadas às características que consideravam essenciais para um profissional de Educação Física, algo que não tinha sido possível no Grupo A.

Todas as entrevistas foram transcritas (97 páginas de dados) e utilizadas para a análise, além das anotaçóes realizadas em cada encontro e do diário de campo, utilizado ao final de cada entrevista. As transcrições foram organizadas na sequência de fala de cada participante, recebendo um código de identificaçáo e o ordenamento, conforme cada contribuição. Com a leitura dos dados transcritos passamos a identificar categorias que apareciam com maior frequência e que apresentavam algum tipo de descrição, qualificação ou introdução de novas ideias. As análises em Grupos Focais seguem duas abordagens: a análise do grupo como um todo e a análise baseada no indivíduo ${ }^{15}$. No primeiro caso, cada grupo é visto como uma unidade de análise. Optamos por utilizar a análise individual a fim de observar como os estudantes entendem os conteúdos de ensino e o processo de formaçáo profissional em Educação Física, levando em consideração a interatividade e a exposição de suas ideias sobre os temas das entrevistas. Desse modo, não são as diferenças entre os grupos A e B, mas as informaçóes que cada participante agrega aos temas em discussáo que compóem o escopo das categorias de análise.

A fase de identificaçáo de categorias levou em consideração três elementos: (1) a profundidade ou extensão dos tópicos gerados no grupo e entre $\operatorname{membros}^{13,16}$ (2) a sequência de transcrição, ou seja, de aparecimento de ideias entre os membros e o seu poder (frequência) para cada membro ${ }^{14}$ (3) o contexto de respostas relacionado ao estímulo (questóes de pesquisa) e à interação com outros membros $^{13}$. Os tópicos de análise gerados dos dados brutos foram relacionados conforme a similaridade de sentidos expressos e, a partir desses núcleos de sentido, foram nomeadas como "categorias". Cada núcleo representou, portanto, um grupo semântico de informaçóes explicado pelo referencial teórico utilizado no estudo.

\section{Resultados e Discussão}

Ao mapear como cada participante optou pelo curso, tornou-se possível entender o processo de formaçáo pelo qual os graduandos estavam passando e, mais especificamente, o que pensavam sobre o curso de Educação Física. As ideias geradas no grupo focal sobre a graduação estavam corriqueiramente presentes nas arguiçôes dos alunos. Com a organização da leitura, tabulação e análise do material, identificamos duas categorias temáticas e subcategorias que ilustram as expectativas dos universitários ao se formarem e como avaliavam seu processo de formação. As duas categorias 
temáticas foram as seguintes: a) consideraçôes sobre o curso de formação e expectativas para o campo profissional, que retratou o impacto da configuração curricular do curso, o processo de interação do aluno com o campo profissional e as percepçóes dos alunos sobre o impacto da ação docente na orientação profissional; b) Uso dos conhecimentos pelos estudantes de Educação Física, que descreve as características das experiências estabelecidas para ampliar a rede de conhecimentos no processo de formação e como os alunos classificam e priorizam suas relações pensando na inserção no mercado de trabalho. Cada categoria e suas subcategorias originadas serão apresentadas a seguir.

\section{Percepçóes sobre o curso de formaçáo e expectativas para o campo profissional na Educaçáo Física}

\section{Experiências práticas na formaçáo orientam os alunos a pensar como seu futuro aluno/cliente $e$ náo a pensar como futuros profissionais}

Ao descrever as ideias emergidas no Grupo Focal sobre o curso de formaçáa, algumas falas dos alunos evidenciaram os contornos que os conteúdos e as experiências no decorrer da sua preparação tomaram, não apenas sinalizando as características da estrutura do próprio curso, mas também as características dos elementos considerados relevantes à trajetória profissional. Na visão do participante $6 \mathrm{~A}$, o curso de Educação Física é "muito dinâmico e oferece várias opçóes”. O participante 7A complementa ao relatar que existem muitas opçóes no curso e projetos nos quais podem se envolver no meio acadêmico, em diversas áreas, citando como exemplo as áreas de saúde e esporte. O participante 5A foi espontâneo ao alegar que o curso é "bem prático, difícil, mas bem prático"; que "têm aulas na piscina, quadra, academias, escolas, joga bola, tem a parte teórica, mas é bem prático". Nesse caso, a ideia de "prático" que está sendo colocada pelo participante não remete necessariamente à exclusividade de conteúdos técnico-instrumentais, mas sim à pluralidade das vivências que são oferecidas no curso.

Esse aspecto surge novamente com a participante 2A quando contextualiza as experiências que vivenciou como aluna, deixando claro uma das grandes dificuldades que a Educação Física ainda apresenta no processo de preparação profissional: "a gente vê (conteúdos) bem rapidamente na teoria e às vezes vai lá na quadra. O professor vai exemplificando né, mas logo em seguida a gente vai praticar como se a gente fosse o aluno e depois a gente não consegue colocar em prática com o outro [...]". O relato ressalta uma questáo importante no contexto do ensino superior da Educação Física: A primeira questáo refere-se à forma como os conteúdos de ensino são transmitidos. Para muitos professores, a aula "prática" no ensino superior ainda é direcionada para a vivência das atividades e não para a elaboração, por parte do aluno, de práticas de ensino ou aplicação de conhecimentos (técnicos e conceituais) nos diferentes campos de atuação possíveis.

Em síntese, o que parece ser um sentimento geral dos estudantes é que a formação universitária é insuficiente para atender à demanda no mercado de trabalho ${ }^{17}$. A insatisfação com a relação teoria e prática na formação decorre basicamente do 'descompasso entre o curso básico e o profissionalizante e, no caso das disciplinas profissionalizantes, os professores não têm a experiência necessária para oferecer modelos práticos derivados das teorias estudadas e analisadas no curso' ${ }^{17}$ (p. 305).

Quando falamos da atuação de um profissional que precisa decidir, criar, adaptar ou modificar um ambiente em que sua intervençáo é fundamental, não podemos nos conformar com a relação dual entre teoria e prática como se um fosse subjugado ao outro. Por isso, para Assad e Viana ${ }^{18}$, transformar o ambiente de trabalho em laboratório de aprendizagem, provendo-o de infraestrutura para partilhar, construir e divulgar o conhecimento profissional, é o caminho mais consistente para ensinar o aluno a pensar como um profissional. Vivenciar práticas fictícias na posição de aluno, e não na condição de profissional-interventor, não parece ser a estratégia mais adequada a ser utilizada nos cursos de formação profissional em Educação Física.

Silva, Zanelli ${ }^{19}$ realizaram um estudo com docentes para entender a relação entre o discurso real e o discurso ideal sobre a formação profissional na Educação Física. Para os autores, ficou evidente que 'a docência universitária está associada ao produtivismo acadêmico, competitividade e o individualismo sobre o status docente' (p. 139). Estes fatores acabam recaindo sobre a qualidade da formação profissional intimamente relacionada 'as insatisfatórias condições estruturais, físicas, pedagógicas e metodológicas que sustentam a formação nos diversos níveis desta área, desde a graduação até o doutoramento ${ }^{19}$. 
A divisáo do curso em bacharelado e licenciatura é vista como barreira para a inserçáo no mercado de trabalho

Mesmo sabendo que a Educação Física, ao longo das últimas décadas, conquistou espaço e certo status científico, ela ainda enfrenta problemas em sua caracterização acadêmica e profissional. De um lado existe a orientaçáo política de que é uma área das ciências da saúde e, por outro lado, existem indicaçôes de que não seria "apenas" uma área da saúde. Segundo LazzarotTi Filho et al. ${ }^{20}$, esta dupla caracterização têm grandes consequências, pois no interior das ciências da saúde há larga hegemonia da lógica das ciências biológicas. Sua forma de produzir conhecimento acaba desconsiderando as formas de produzir conhecimento nas ciências humanas, gerando obstáculos ao seu desenvolvimento no âmbito das práticas corporais.

Reforçando as consequências que a disputa entre os campos da saúde e ciências humanas exercem na formação inicial, o sujeito $6 \mathrm{~A}$ ilustra que o curso de formação "tem muito foco na escola", pois "o profissional é formado para a escola, ainda mais com essa divisão curricular". Para o participante, a divisão entre bacharelado e licenciatura prejudicou sua formação e suas possibilidades no mercado de trabalho, já que ele tem maior interesse na área não escolar.

Para os alunos participantes da pesquisa, ainda existem algumas fragilidades que precisam ser vencidas para atender às necessidades de melhor atuação profissional. $\mathrm{O}$ participante $7 \mathrm{~A}$ alega que essa divisão não foi feita de forma que as pessoas pudessem se adequar e, como consequência, os professores "dão quase a mesma coisa (nas aulas) com uma mudança bem de leve", tanto para o bacharelado quanto para a licenciatura. O participante P7A complementa: 'Só ta impedindo de trabalhar na escola com formaçáo de bacharel”. Essas argumentaçôes parecem representar a insatisfação dos alunos com a separação do curso em duas habilitações da forma como estão organizadas. Para PRONI ${ }^{21}$, a separação entre licenciatura e bacharelado acabou dividindo e enfraquecendo a identidade acadêmica da Educação Física e produziu uma distinção entre o professor de Educação Física e o profissional das Ciências do Esporte. Para o autor, as faculdades ao procurarem adequar a formaçáo específica desses profissionais aos novos requisitos do mercado de trabalho oferecem uma formaçáo única ou se aproveitam de diferentes nichos de mercado e apostam na especialização. Mas, o mercado também cobra das faculdades a superação de certas carências ${ }^{21}$. As consequências recaem na condição da organização institucional das universidades.

[...] a atuação docente é afetada pelo problema da falta de uma política institucional explícita e intencional de capacitação de seus docentes ${ }^{\prime 22}$ (p. 64), o que dificulta a melhora da qualidade do ensino. $\mathrm{O}$ quadro que se instalou nas universidades nos últimos anos foi de forte investimento na pesquisa. A titulação, a publicação científica, a orientação em projetos de iniciação científica e a pós-graduação passaram a ser prioridade do corpo docente dos cursos de Educação Física dessas universidades ${ }^{23}$, colocando em dúvida a qualidade da formação profissional.

Para o entrevistado 'P8A: a maioria dos professores falam pra gente fazer o bacharelado e a licenciatura, pra, é garanti emprego, concurso, tem mais garantia'. Essa passagem demonstra que a possibilidade de escolhas no mercado de trabalho acaba induzindo os alunos a se formarem em duas habilitações e, optam pela segurança de poder atuar em qualquer campo da Educação Física, tanto escolar quanto os campos mais genéricos do exercício profissional.

\section{Quem se destaca na área já teve formação prática anterior á graduaçáo ou se especializou na pós-graduaçâo}

A ansiedade em relação à inserção no mercado de trabalho acaba influenciando as escolhas que os alunos fazem no curso. É a partir dessa preocupação que os estudantes avaliam o que "é útil" para ser aprendido e aplicado futuramente, principalmente quando os universitários estáo nas últimas fases do processo de formação e intensamente envolvidos com as vivências do estágio, nos campos de intervenção. Além do conhecimento, as crenças e os valores influenciam nas decisóes sobre quais conteúdos utilizar e quais julgamentos sobre o processo de atuação irão fazer. Por este motivo, ENNIs ${ }^{24}$ atribui às crenças uma forma de conhecimento condicional, atrelado às situaçôes que serão encontradas pelo profissional no campo de intervenção.

Valores, crenças, atitudes, normas, conceitos, habilidades e outros saberes aparecem nas relaçóes sociais presentes nos cursos de graduação e formam uma cultura universitária da Educação Física, que merece ser compreendida ${ }^{25}$, principalmente quando reconhecemos que a Educação Física foi e continua sendo construída no mundo prático, da prática corporal, cultural, política e social. 
É nesse caminho que se justificam as impressóes dos alunos sobre os profissionais de sucesso nos campos especificamente práticos, como ilustra o diálogo a seguir:

P4B : "quem se destaca nessas áreas normalmente já teve formaçáo anterior";

P3B: "é, foi atleta";

P4B : "ou se esforçou muito e se especializou pra poder ser um técnico [...]";

Nos trechos acima, a experiência prévia em certo contexto prático de atuaçáo será o diferencial para o sucesso profissional. De certa forma, NAscimento et al. $^{26}$ afirmam que as vivências práticas precisam ser fomentadas na formação inicial, mas não podem limitar-se ao simples desenvolvimento de habilidades esportivas, mas em todos os sentidos, deve ser ressaltado o papel profissional que o aluno irá assumir futuramente, exigindo reflexão crítica sobre aquilo que irá desempenhar e das responsabilidades ligadas a sua intervenção.

Pimenta $^{27}$ realizou um estudo procurando identificar se os professores de uma instituição superior, responsáveis pelas disciplinas esportivas, sistematizavam e aplicavam em sua prática pedagógica os conhecimentos produzidos pela área da Aprendizagem Motora para o ensino de habilidades esportivas. O autor identificou que os conceitos ou estratégias preconizadas pela Aprendizagem Motora, quando utilizados, são aplicados de forma aleatória induzindo o docente a uma falsa percepçáo de aprendizagem dos conteúdos "práticos" na disciplina. Isso demonstra que, ainda hoje, o ensino perfaz uma orientação tradicional que se pauta na experiência acumulada pelo professor e não em princípios científicos para o ensino de tais conteúdos.

Como consequência, os alunos se sentem inseguros com o que aprendem na Universidade e a continuidade da formação para além da graduação parece ser o item primordial a ser considerado para ter chances no mercado de trabalho. Como o participante 3B ilustra: "É preciso ter várias pósgraduaçôes para poder ter um conhecimento, pra poder ta realmente no mercado"; PB5: "e é até perigoso você ser julgado que você ficou só na teoria e por não ter a prática”. Para $\mathrm{BARATO}^{3}$, o padrão rígido de explicação de que a teoria vem antes da prática predomina no processo pedagógico e isso tem consequências na formação profissional. A naturalização da hierarquia da teoria sobre a prática distancia os universitários das expectativas positivas sobre sua capacidade de agir no mercado de trabalho.

\section{O uso dos conhecimentos pelos estudantes de Educaçáo Física}

\section{O curso acaba sendo um mostruário. É preciso continuar se especializando}

Os estudantes de Educação Física participantes da pesquisa visualizam a breve entrada na carreira como uma fase de "sobrevivência". Segundo Huberman ${ }^{28}$, essa fase se traduz como choque com o real - a confrontação inicial com a complexidade da situação profissional - distanciando-se dos ideais e das realidades cotidianas. Em contrapartida, existe a fase da "descoberta" que se traduz no entusiasmo, na experimentação e na situação de ser responsável por alguma tarefa. É por este conjunto de sentimentos que o processo de formação e inserção profissional torna-se rico e complexo.

Algumas falas dos próprios discentes contribuem para apresentar como se sentem frente aos conteúdos curriculares. O participante $3 \mathrm{~A}$ cita que "o curso acaba sendo um mostruário pra gente [...]. A gente conhece, mas pra gente ficar bem mesmo não vai ser com o que a gente tem no curso. Vamos ter que fazer pós, cursos [...]”. Para este participante, os conteúdos aprendidos na formaçáo inicial não atribuem segurança ao seu futuro profissional. A maioria dos alunos participantes mencionou nas entrevistas que, um dos grandes responsáveis pela dificuldade de serem bem qualificados é o tempo das aulas e a quantidade das informaçóes que precisam captar. Os alunos, nesse caso, demonstram que estão preocupados com a forma como são preparados e não esperam receber as informações prontas, mas consideram a necessidade de articular as informações em atividades que problematizem o contexto profissional.

O aluno P7A exemplifica: "em bioquímica, a gente tem que aprender todos aqueles conceitos; Fica difícil a gente aprender como funciona o organismo lá dentro; a gente não vai usar aquilo [...]". Mesmo com a fundamental necessidade dos conteúdos biológicos para a preparação do profissional de Educação Física, para o aluno, o conteúdo fica distante da aplicabilidade ou de algum tipo de contextualizaçáo com a realidade profissional. Como consequência, ele acaba minimizando a presença de tal conhecimento nos momentos de tomada de decisão. 
Determinar a realidade por conceito, fato ou princípio não é algo isolado, mas sua profundidade, extensão e seus significados dependem das relaçóes significativas com outros conceitos ${ }^{29}$ (p. 309). O ensino geralmente acontece em duas partes: a primeira que estabelece $\mathrm{o}$ ato de aprender pelos conteúdos de ensino disciplinares e a segunda refere-se à fase de observação do funcionamento dos mecanismos vistos anteriormente. $\mathrm{O}$ ensino fragmentado

[...] faz do iniciante o retrato de uma pessoa que, a par da formação recebida, está condicionado a recortar a realidade em uma infinidade de componentes, a avaliar que no momento de intervir é importante considerar igualmente cada um desses componentes, a imaginar que uma boa intervenção é necessariamente refletida, e crer que terá todo o tempo para refletir sobre sua ação, a pensar que o domínio de conhecimentos teóricos fragmentados é a chave de uma intervenção bem sucedida e a considerar que o êxito profissional será proporcional à sua aptidão para ativar um "programa especifico de intervençáo"30 (p. 76).

Corre-se o risco de considerar os alunos desinteressados ou descompromissados com sua formação, mas, na verdade, os estudantes são instruídos a ter uma visão fragmentada das situaçóes, ou até mesmo ilusória ao se depararem com a complexidade da realidade cotidiana do profissional. Os acadêmicos passam a acreditar que o que sabem não é o suficiente para a intervençâo e que precisam continuar adquirindo novos saberes, como fica claro na sequência de falas abaixo:

P2A : "você tem que estudar mais fora daqui do que aqui $[\ldots]$ "

P7A : "é, aqui só pega um direcionamento e você que vai".

P3A "[...] quando a gente sair daqui vamos tá entrando no mercado de trabalho então eu começo a ter essa visão de que eu preciso tá andando com as minhas próprias pernas [...]".

Pelo crescente desenvolvimento na produçáo de conhecimento, a necessidade de atualização constante faz parte do senso comum de qualquer área. A busca por experiências fora da universidade acaba sendo estratégia para aproximar as habilidades exigidas pelas demandas sociais, depois da formação inicial. Daí que um elemento citado pelos sujeitos para fortalecer os fundamentos da atuação profissional são os "cursos" extra-curriculares, de interesse do próprio aluno, para instrumentalizá-lo nas demandas mais comuns em campos como academias, no esporte, recreação entre outros.
Peres e ANdRAdE ${ }^{31}$ realizaram um estudo com alunos de Medicina para identificar o papel que as atividades extracurriculares tinham para a formação. Segundo os autores, a exaltação de atividades extracurriculares é vista como fator contribuinte para amenizar conflitos com o curso ou complementar o currículo oficial. Entretanto, o principal fator em questão é que as expectativas não contempladas por um currículo instituído pode criar um currículo paralelo por meio das atividades extracurriculares, com a funçáo de facilitador do desenvolvimento psicossocial e cognitivo, do rendimento acadêmico e principalmente do ajustamento dos estudantes à Universidade.

\section{Além de conbecimentos novos a forma como sáo empregados sáo os principais fatores para a diferenciaçáo profissional do mercado de trabalbo}

Em geral, os alunos reconhecem a necessidade de inovar e procurar outras alternativas para adquirir conhecimentos que poderão complementar sua formação. Nessa direção, concordamos com Pimenta $^{32}$ quando diz que a formação é, na verdade, autoformação, uma vez que os profissionais reelaboram os saberes iniciais em confronto com suas experiências práticas. Para $\mathrm{S}_{\mathrm{CHÖN}}{ }^{33}$, a consciência dos saberes envolvidos na ação é aprendida se houver reflexão sobre os mecanismos envolvidos nas práticas dos profissionais. Mas, esse é um processo que precisa ser estimulado desde os primeiros anos da formaçáo inicial.

O aluno P2A relata a importância de estar em um grupo de pesquisa e ressalta que isso foi um diferencial em sua formação. Para o aluno P3A, "na universidade o que é mais importante é isso; não necessariamente todos têm que seguir esse caminho, mas tudo que é produzido [na universidade] é o que te diferencia lá fora, tanto com outro profissional competindo lá fora quanto com o leigo".

Os grupos de pesquisa e de extensão, certamente, são algumas das estratégias utilizadas pelos alunos para a aquisição de conhecimentos que ofereçam suporte para o que vivenciam nas disciplinas e ao que irão encontrar fora da universidade. São estratégias importantes de formação complementar, uma vez que o curso de Educação Física, por suas características abrangentes de formação, não visa à especificidade em um campo profissional. Isso viria a posteriori, na formação continuada. 
As ideias dos acadêmicos acerca do trato dos conteúdos da Educação Física, além de influenciar como devem se orientar para aprender novas informaçôes, constituem aspecto importante de manutenção profissional. A forma como os alunos/ profissionais utilizam os saberes aprendidos na formação é chamada por Аввотт ${ }^{34}$ de inferência. Segundo o autor, inferir é o puro ato profissional porque é como ele usa as informaçóes inicialmente diagnosticadas, analisa as possibilidades diante do seu cenário e toma decisóes sobre como agir. Para isso, o profissional precisa saber reconhecer os conhecimentos e saberes que o façam elaborar e considerar o impacto de seus atos. É essa qualidade que deve ser aperfeiçoada no processo de formação profissional. Como sinaliza um entrevistado: "[...] a pessoa que vai se formar comigo tem o mesmo conhecimento que eu; a diferença é que na hora ela vai dar um treino, de repente passa pro cara um anabolizante ou alguma coisa que vai fazer mal pra ele e fez o mesmo curso que eu. Então, não sei se é só o curso que vai mudar a atuação" (Participante 4B). É nesse sentido que a capacidade de avaliar e ponderar condutas diante de cada situação deve ser aguçada porque as escolhas sobre como agir diante de situaçóes-problema não remetem apenas ao conteúdo curricular.

Os aspectos "ocultos", relacionados aos valores morais e de atitudes, são fundamentais. Segundo o participante 2B: "[...] por mais que hoje a gente tenha conhecimentos novos, acho que isso não é o principal pra definir a diferença pra um profissional e outro". TARDIF $^{35}$ explica que para profissionais construírem seu repertório de ação é fundamental que os saberes disciplinares, oriundos da tradição cultural e dos grupos produtores de saberes, sejam confrontados aos saberes ligados ao seu trabalho cotidiano.

Nesse cenário, o estágio seria o momento de maior esperança do aluno para aplicar aquilo que aprendeu na universidade. Contudo, muitas vezes os alunos encontram profissionais que não têm orientaçóes objetivas sobre o que deve ser transmitido ao estagiário que vivencia seu campo de trabalho. $\mathrm{O}$ aluno, futuro profissional, sente-se inseguro, vulnerável às condiçóes e responsabilidades que deverá assumir como profissional e, dessa forma, é pressionado a continuar seus estudos para assegurar condições que the possibilitem competir no mercado de trabalho. Como alternativa às necessidades imediatas para a inserção no mercado, a experiência acumulada, os cursos práticos de capacitação oferecidos por empresas do fitness ou as experiências como atletas ainda são valorizados pelos alunos como diferencial à formação para suprir as supostas limitaçóes das experiências profissionais no decorrer da formação universitária.

\section{Algumas consideraçóes sobre a formação profissional na Educaçáo Física}

De forma geral, ter consciência sobre aquilo que se sabe é algo difícil diante do volume de conteúdos aprendidos no decorrer da formação. A reflexão acerca do processo de tomada de decisóes, do quanto isso é complexo e pouco discutido nos cursos de formaçáo é cada vez mais necessária. A "vida profissional” tem múltiplas dimensóes, que passam pelas escolhas, condutas, julgamentos, muitas vezes orientados por experiências que aconteceram mesmo antes da entrada na universidade. Ainda é necessário pensar em novos estudos orientados a evidenciar que tipo de conhecimento realmente estamos valorizando ao longo da formaçáo e como tem se dado a transposiçáo daquilo que é ensinado para aquilo que é utilizado, predominantemente para os jovens profissionais.

Se uma boa formaçáo é aquela que usa de todo o repertório científico para preparar o aluno para a vida profissional, estamos esquecendo que a "vida profissional" tem uma concepção muito mais ampla que passa pelas escolhas, condutas, julgamentos, muitas vezes orientados por experiências que aconteceram mesmo antes da entrada na universidade, que tiveram seu peso nas motivações de cada sujeito, as quais os impulsionaram à Educação Física. É preciso redimensionar o saber que constitui o fazer da realidade profissional.

$\mathrm{Na}$ universidade, os projetos extracurriculares são considerados um reforço ao que é desenvolvido nas disciplinas, tanto como suporte para atuação profissional quanto para maior facilidade de entendimento dos conteúdos apreendidos. Contudo, com a exacerbada valorização da pesquisa, a natureza do caráter pedagógico do ensino foi substituída pela produção e discussão de pesquisas geradas pelos professores-pesquisadores e a preocupação em "formar" o profissional ficou em segundo plano. A pesquisa e o ensino, na universidade, supóem características diferenciadas. $\mathrm{O}$ ensino pressupóe a ação de alguém que ensina algo para outra pessoa. A pesquisa, mesmo quando voltada para seres humanos, pretende produzir novos conhecimentos, novas técnicas e não tem por foco, como é o caso do ensino, a formação de alguém ${ }^{36}$. Como consequência, a visão dos alunos em relação à busca de conhecimentos acabou sendo fortemente 
relacionada às vivências práticas nos campos profissionais, porque suprem suas necessidades imediatas para a inserção no mercado de trabalho, diferente do conhecimento básico que precisa ser compreendido, contextualizado e ressignificado para cada situação-problema.

SchöN ${ }^{33}$ sinaliza que, para alguns estudiosos da prática profissional, aquele considerado mais competente acaba sendo caracterizado dessa forma por ter mais "talento", "intuição" ou "talento artístico". Mas, se definirmos os profissionais com essas expressóes, acabamos por anular diversas possibilidades ligadas às categorias do profissionalismo, como a ética, a virtude, o altruísmo e a inferência. Estes elementos vão sendo incorporados às representaçóes que os universitários constroem sobre a carreira e ao papel profissional no processo de formação.

Como observado nos dados dos grupos focais, por um lado, os participantes dos primeiros anos (concentrados no Grupo A), quando pensam na carreira pós universidade, tendem a valorizar a continuidade dos estudos e o aprofundamento dos saberes vinculados aos projetos de pesquisacomo caminho para a capacitção especializada. Por outro lado, apesar do ponto de vista similar entre os alunos dos primeiros e dos últimos anos em relação à necessidade da capacitação continuada após a universidade, os aspectos éticos e morais tonam-se mais presentes nas descriçóes sobre o que define o 'profissional diferenciado' no mercado de trabalho.

Na prática profissional, o senso da ação perfaz o 'fazer da forma correta', com a atitude correta, ou seja, com integridade. Por sua vez, o senso de integridade emerge da prudência profissional que, em outras palavras, é a qualidade de perceber de forma acurada o que é requerido em uma ação ${ }^{37}$.

Vemos, então, que a formação profissional tem dupla responsabilidade: ensinar os conteúdos que perfazem a área e ensinar os alunos-profissionais a refletirem e relacionarem tais conteúdos em cada contexto de atuação. Portanto, tal relação entre conhecimento dos conteúdos (saber) e o conhecimento dos conteúdos para o agir profissional (fazer), indica que uma dimensão sozinha não garante o sucesso da outra ${ }^{5}$. Ambas precisam estar presentes na dinâmica do ensino profissional.

Segundo Bracht ${ }^{38}$, 'a Educação Física é uma prática de intervenção e o que a caracteriza é a intenção pedagógica' (p. 33). Por outro lado, para o autor, é esta orientação prática que complexifica o teorizar na Educação Física. O saber prático ou corporal resiste à teorização, porque é permanentemente mutável. Por isso, a compreensão da intervenção e formação profissional 'torna-se um dos maiores desafios já que sua complexidade não consiste apenas na aquisição do conhecimento acadêmico, mas também na articulação de diversos tipos de saberes, de recursos e ainda capacidade de resolução de problemas profissionais ${ }^{39}$.

Feitos esses apontamentos, alguns caminhos podem ser considerados para minimizar as fragilidades no processo de formaçáo profissional:

É preciso valorizar as pesquisas voltadas ao levantamento das informações sobre o processo de transição do universitário para o status de profissional e mapear suas concepçóes e como sistematizam os saberes para a tomada de decisão ao longo da transição aluno-profissional.

A expectativa para a continuidade da formação nos diversos níveis representa que o universitário está engajado com sua carreira e procura se especializar para, assim, conquistar melhor status que reflita em seu reconhecimento. Desse modo, as percepçóes dos estudantes sobre a sua formaçáo e as expectativas para a sua carreira são preciosas informaçóes que devem ser consideradas nas discussóes em sala de aula, assim como o contato com outros profissionais, cursos e projetos são recursos fundamentais para a aquisição de conhecimentos que diminuam as incongruências entre a carreira idealizada e a vivenciada.

É preciso pensar nas avaliaçôes institucionais dos estudantes e egressos como importantes ferramentas para o delineamento de açóes e ajustes nos currículos, nas práticas de pesquisa, nas possibilidades de experiências profissionais e, principalmente, de preparação para a carreira no campo da Educação Física, amparando tanto os egressos quanto o próprio curso de formação.

Em suma, a formação profissional de qualidade deve, cada vez mais, incorporar os espaços extramuros das universidades como ambientes de ensino e aprendizagem. O reconhecimento da interdependência entre o conhecimento formalizado e o conhecimento da ação exige cada vez mais atitudes e estratégias reflexivas e, a componente chave para a construção da ponte entre ser e fazer está na capacidade de discernir, decidir e deliberar, náo pela razáo técnica apenas, mas pela forma como o sujeito se auto define em face a um cenário profissional. Na sociedade do conhecimento, o "estado de conhecer" precisa mediar as relaçóes entre os sujeitos e a realidade. 


\section{Abstract}

\section{What students think about professional formation in physical education}

This study aimed to verify what students think about the process of professional formation and what guidance the students themselves for the selection of relevant knowledge to subsidize their professional performance. To this end, we chose the research technique of focus groups, with two groups of Physical Education students of Maringa State University. In one group, we had seven students from first to third year of the course and the other group made up of five students from the third and fourth graduation year. Each meeting originated video and audio data, transcribed and analyzed later to identify standards applicable to the problem of study. We identified two themes: a) Considerations about the training course and expectations for professional field in Physical Education, which portrayed the impact of curricular setting of the course and the impact of teacher action on career orientation; b) the use of knowledge by students of Physical Education, which describes the characteristics of knowledge networks established by students in the formation process. These categories shows that the demands in the labor market has led the professional training to adapt their content and curricula, although these changes were not reflected in terms of professional formation, nor beheld the conceptions of teachers in relation to professional education, highlighting weaknesses in the logic of university formation.

KeYwords: Professional choices; Focal group; Knowledge; Professional education.

\section{Referências}

1. Gamboa SS. Epistemologia da educação física. Maceió: Edufal, 2007.

2. Frizzo GFE. A produção do conhecimento da educação física no Programa de Pós-Graduação em Ciências do Movimento Humano da UFRGS. Pensar Prát. 2010;13(3):1-16.

3. Barato JN. A técnica como saber: investigação sobre o conteúdo do conhecimento do fazer [tese]. Campinas (SP): Universidade Estadual de Campinas; 2003.

4. Britto LPL, Silva: EO, Castilho KC, Abreu TM. Conhecimento e formação nas IES periféricas perfil do aluno "novo" da educação superior. Avaliação. 2008;13(3):777-91.

5. Marcon D. Construçáo do conhecimento pedagógico do conteúdo dos futuros professores de Educação Física [tese]. Porto: Universidade do Porto; 2011.

6. Oliveira CT, Santos AS, Dias ACG. Percepçôes de estudantes universitários sobre a realização de atividades extracurriculares na graduação. Psicol Ciênc Prof, 2016 [citado 2019 fev. 28];36(4):864-76. Disponível em: https://dx.doi.org/10.1590/19823703003052015 .

7. Snape D, Spencer L. The foundations of qualitative research. In: Richie J, Lewes J. Qualitative research practice. Thousand Oaks: Sage; 2008. p. 1-23.

8. Piovesan A, Temporini ER. Pesquisa exploratória: procedimento metodológico para o estudo de fatores humanos no campo da saúde pública. Rev Saúde Pública. 1995;29(4):318-25.

9. Minayo MCS. O desafio do conhecimento: pesquisa qualitativa em saúde. 8a ed. São Paulo: Hucitec; 2000.

10. Carlini-Cotrim B. Potencialidades da técnica qualitativa de grupo focal em investigações sobre o abuso de substâncias. Rev Saúde Pública. 1996;30(3):285-93.

11. Kamberelis G, Dimitriadis G. Focus groups: strategic articulations of pedagogy, politics and inquiry. In: Denzin N, Lincoln Y, organizadores. Handbook of qualitative research. 2a ed. Thousand Oaks: Sage; 2000. p. 887-907.

12. Madriz E. Focus groups in feminist research. In: Denzin N, Lincoln Y, organizadores. Handbook of qualitative research. 2a ed. Thousand Oaks: Sage; 2000. p. 235-50.

13. Krueger R. Focus groups: a practical guide for applied research. 2a ed. London: Sage; 1994.

14. Gatti BA. Grupo focal na pesquisa em ciências sociais e humanas. Brasília: Líber Livro; 2005.

15. Ritchie J, Spencer L, O’Connor W. Carrying out qualitative analysis. In: Richie J, Lewes J. Qualitative research practice. Thousand Oaks: Sage; 2008. p. 219-62.

16. Twinn S. The analysis of focus group data: a challenge to the rigour of qualitative research. J Res Nurs. 2000;5(2):140-46. 
17. Gondim SMG. Perfil profissional e mercado de trabalho: relação com a formação acadêmica pela perspectiva de estudantes universitários. Estud Psicol (Natal). 2002;7(2):299-309.

18. Assad LG, Viana LO. Saberes práticos na formação do enfermeiro. Rev Bras Enferm. 2003;56(1):44-7.

19. Silva RA, Zanelli JC. O discurso real e o discurso ideal de professores de Educaçáo Física do ensino superior sobre docência. Movimento (Porto Alegre). 2010;16(3):133-54.

20. Lazzarotti Filho A, Silva AM, Antunes PC, Salles da Silva AP, Leite J. O termo práticas corporais na literatura científica brasileira e sua repercussão no campo da Educação Física. Movimento (Porto Alegre). 2010;15(1):11-29.

21. Proni MW. Universidade, profissão educação física e mercado de trabalho. Motriz. 2010;16(3):788-98.

22. Nascimento JV. Formação do profissional de educação física e as novas diretrizes. In: Neto SS, Hunger D, organizadores. Formação profissional em Educação Física. Rio Claro: Biblioteca; 2006. p. 59-75.

23. Hunger DACF, Souza Neto SS, Pereira JM, Franco FC, Rossi F. Formação acadêmica em Educação Física. Motriz. 2009;15(1):79-91.

24. Ennis CD. Knowledge and beliefs underlying curricular expertise. Quest. 1994;46:164-75.

25. Freire ES. Preparação profissional em Educação Física. REMEFE. 2007;6:147-54.

26. Nascimento JV, Ramos V, Marcon D, Saad MA, Collet C. Formação acadêmica e intervenção pedagógica nos esportes. Motriz. 2009;15(2):358-66.

27. Pimenta BJF. Descrição dos saberes sobre a aprendizagem motora por docentes universitários [monografia]. Londrina (PR): Universidade Estadual de Londrina; 2011.

28. Huberman M. O ciclo de vida profissional. In: Nóvoa A, organizador. Vidas de professores. Porto: Porto; 1992. p. 31-59.

29. Coll C, Pozo JI, Sarabia B, Valls E. Os conteúdos na reforma: ensino e aprendizagem de conceitos, procedimentos e atitudes. Porto Alegre: Artmed; 2000.

30. Carboneau M, Hétu JC. Formação prática dos professores e nascimento de uma inteligência profissional. In: Paquay L, organizador. Formando professores profissionais: quais estratégias? Quais competências? Porto Alegre: Artmed; 2001. p. 67-84.

31. Peres CM, Andrade AS. Atividades extracurriculares: percepçôes e vivências durante a formaçáo médica. In: Biasoli-Alves ZMM, Alves IMFM, organizadores. Programa de Pós-Graduação em Psicologia-FFCLRP-USP. Ribeirão Preto: Legis Summa; 2005. p. 153-63.

32. Pimenta SG. Formação de professores. In: Pimenta SG, organizador. Saberes pedagógicos e atividade docente. 2a ed. São Paulo: Cortez; 2000. p. 15-34.

33. Schön DA. Educando o profissional reflexivo: um novo design para o ensino e a aprendizagem. Porto Alegre: Artmed; 2000.

34. Abbott A. The system of professions. Chicago: University of Chicago Press; 1988.

35. Tardif M. Saberes docentes e formaçáo profissional. 13a ed. Petrópolis: Vozes; 2012.

36. Kougnoff W. A face oculta da universidade. São Paulo: Editora da Unesp; 1990.

37. Lebacqz K. Professional ethics: power and paradox. Nashville: Abingdon Press; 1992.

38. Bracht V. Educação Física e ciência: cenas de um casamento (in)feliz. 3a ed. Ijuí: Editora Unijuí; 2007.

39. Soriano JB Formação profissional em educaçáo física: da orientação acadêmica à intervenção profissional. REMEFE. 2010;9 (Supl 1):21-5.

\section{Agradecimentos}

Pesquisa financiada pelo Conselho Nacional de Desenvolvimento Científico e Tecnológico (CNPq).

Agradecemos a generosidade, o cuidado e a seriedade nas recomendaçóes dos pareceristas à este trabalho, as quais foram fundamentais para avanços na qualidade do texto.

\begin{tabular}{r|r} 
ENDEREço & \\
Rubiane Giovani Fonseca & \\
Universidade Estadual de Londrina & Recebido para publicação: 24/02/2015 \\
Rodovia Celso Garcia Cid, PR-445, Km 38 & Revisado: 16/10/2017 \\
Campus Universitário & Aceito: 29/03/2018 \\
86044-766 - Londrina - PR - BRASIL & \\
e-mail: rubianegf@hotmail.com &
\end{tabular}


